\title{
Coincidence of Marx and the Traditional Culture in Development Thoughts of Human Beings and Its Contemporary Values
}

\author{
Zhao SUN \\ Shandong Foreign Languages Vocational College, No. 99 Shanhai road, Rizhao city, \\ Shandong province, China \\ Eoscar198781@163.com
}

Keywords: Marx, Traditional Culture, Development Thoughts of Human Beings, Coincidence and Contemporary Values

\begin{abstract}
The related research on the development thoughts of human beings has played an important role in people's development and social development, and the academic circle has always given high attention to Development Thoughts of Human Beings, therefore, it is extremely important to carry out the corresponding discussions for this part. This article is mainly divided into three parts, the first part mainly discuss Marx's Theory of All-round Development and Human Theory to make the readers understand these two theories; the second part, combining theories, mainly analyze the coincidence of Marx and the traditional culture in development thoughts of human beings; the third part mainly analyze the contemporary values for Theory of All-round Development and Human Theory.
\end{abstract}

\section{Introduction}

Talent is the core power of social development, and the continuous development of people is also the goal and motivation of human's continuous efforts. For individuals, the human development is the goal of their efforts, for society, it is the source of continuous progress of society. In the running of contemporary society, the concern for human development is the necessity of social development, and the attention to the development thoughts of human beings also has extremely important significance for personal growth and social development and progress. Both Marx's theory of all-round development of human beings and Human Thoughts from China's traditional culture is the important constituents of the theory system of development thoughts of human beings. Based on the actual situation, I will make the corresponding analysis on the theory of all-round development and human thoughts and then discuss the coincidence between these two ideas and the development thoughts of human beings and the contemporary values, which has an extremely important practical value.

\section{Elaboration of Marx's Theory of All-round Development and Human Thoughts}

The All-round development of human beings is the core of Marxist philosophy when it is established and the theory of all-round development is also the key part of Marxist philosophy, which occupies an important position in the whole Marx theory system. In the Marx theory system, the theory of all-round development occupies a dominant position for the development thoughts of human beings. Therefore, we need to figure out the concept of “realistic man” proposed in Marx’s theoretical system before understanding Marx's theory of all-round development. The concept of "realistic man" means the people in development of the real society, this concept is also to better distinguish itself from Hegel's "man of ideas" 
and Feuerbach's “abstract man”. The understanding of "realistic man” is the core basis of understanding Marx's theory of all-round development, and the "realistic man" that is the existence of nature, thinking and society, has rich connotations according to the understanding of human beings from Marx. Its specific content is the followings: a "realistic man", first of all, needs to have the vital signs and is a natural product; secondly, human behavior is dominated and managed by their thinking, and the human is the master of thinking; and thirdly, all human behaviors cannot be separated from society, and social and historical conditions have certain limitations on human behaviors. The word of "all-round" also occupies a very important position in Marx's theory of all-round development. In the view of human from Marx, the individual's development must be comprehensive, that is, cultivate and improve the abilities in all aspects, at the same time; the all-round development of individuals is also a dynamic process that has a rich meaning, including labor skills, social relations and personalities, etc. To summarize, the basic content of Marx's theory of all-round development is: in the thought of human development, human development should be a comprehensive and dynamic process, which has the great and practical significance for human development.

The existence of Chinese traditional culture is the result of the continuous development of history and the union of wisdom of countless ancestors, and the heritage of traditional culture has deeply influenced the current social development and the creation of cultural and social atmosphere. For the development thoughts of the human beings, the corresponding theories covered in our traditional culture have played a certain role in the research activities of its theoretical circle. The Human Thoughts are the main contents of the development thoughts of human beings in the traditional culture, which has certain practical significance on the discussion of the Human Thoughts in the course of exploring the development thoughts of human beings. In our traditional culture, the basic connotations of human thoughts contain the followings: First, the thought of human nature dominated by the theory of "goodness in nature". It mainly mentions that the standard of benevolence shall be followed, in the course of the individual development, to make people treat others with sincerity and develop their own moralities constantly through self-reflection; second, the method people get along with nature on the basis of "harmony between man and nature". In the course of human development, the important development task is to construct the harmonious relation between man and nature and the essence of the idea of "harmony between man and nature" is the recognition for the unity of human's spiritual world and nature, which plays an important role in helping people deal with the relationship between nature and themselves; Third, taking "respecting harmony and balance" as the running rule of the sustainable development of society. "Respecting harmony and balance" is the important part of our traditional culture, which plays an extremely important role in the social and cultural development and has a very important impact on maintaining the social and economic stability. Taking this idea as the method for people to get along with society is also the result of the continuous development of our society, and it also has an important influence on the individuals' development; fourth, "respecting and loving people" is the core thought of human-centered idea. This idea has a very close connection to our historical development because in the historical development course the status of people is very important, the proverbs like "Water can carry a boat, it can also overturn it" and "Take it from people and use it for them" clearly show that our society pay much attention to and cherish people, which is also the key part of the development thoughts of human beings; Fifth, taking "human justice" as the pursuit of the personal development value. The idea of "human justice" is not only an important part of the national 
spirit but also a synonym for strong, and independent in the personal development course. It holds that the main value of life is the enrichment of spiritual and material levels in the course of personal development, which plays an important role in guiding the personal development.

\section{Analysis of Coincidence in the Development Thoughts of Human Beings between Marx and Traditional Culture}

Human Development has always been a hot topic in the academic circles, although the theory of all-round development is not explored in the course of China's historical development, Marx's thoughts still has strong reference to the human development, in addition, the human thoughts in traditional culture also holds the significant and realistic values. Through the analysis and discussion on Marx's theory of development thoughts of human beings and human thoughts, connecting the actual situations, we can see that the coincidence of these two ideas mainly reflects in the following aspects.

\section{Attaching Great Importance to Human Spiritual World}

Attaching great importance to human spiritual world is a great point of coincidence on the development thoughts of human beings between Marx and traditional culture, also the significant contents of these two thoughts. The attention to human spiritual world mainly embodies its emphasis on the improvement of individual moral cultivation and the discussion of ways and methods. Confucianism is a significant part of our traditional culture, in which many ideas on the importance of personal morality have been proposed. Taoism advocates the ideas of "overcoming firmness by gentleness" and "discard all desires and worries from one's mind", which is also the requirement for personal morality. Mohism emphasizes the personal ideal of "mutual respect, mutual benefit". However, Marx's theory of development thoughts of human beings holds that the construction and enrichment of individual's spiritual world is vital and have rich connotation. From the perspective of Marx, people ate the individuals with rich emotion and profound spiritual world, which is also a strong basis for people to distinguish themselves from other animals. In the course of human development, not only the objective perception of the external material society but also the rich connotation should be maintained to create art, music, literature and other ideological things, and the ideological progress effectively promotes social progress and development. In conclusion, both Marx's theory of all-round development and traditional culture emphasize that we should not only pay attention to the cultivation of material sense ability but also pay more attention to the construction and enrichment of personal spiritual world.

\section{The Importance of Adhering to People-based Thoughts}

Insisting on the importance of people-based thoughts is another common point of Marx's all-round development theory and human thoughts from traditional culture. The ideas of "Love the people, values the people and value the people more than the king" proposed in the human thoughts of traditional culture should be possessed by individuals, and then put these ideas into practice. The existence of this thought is the result of the continuous development of our history and has certain influence on the economic and social development. Marx believed that the elimination of private ownership and the construction of communist society are the best condition that the society is striving for, which is actually a sublimation of the people-based thought, reaffirming the importance of the people's power. The existence of this idea has a pretty important effect on the social development of Marx and China. 


\section{Promoting the Concept of Harmonious Development}

"Unity of nature and man" from traditional culture advocates that man and nature are the unity of harmonious coexistence, emphasizing the obedience of the laws of nature, advocating the harmonious and stable development state and calling for "respecting harmony and balance" that is an interpretation of the concept of harmonious development. Marx once said: "we, together with our fresh and mind, belong to nature and exist in nature." Marxism believe that everything has its opposite and unified surface, therefore, the individuals should pay attention to the coordination and cooperation between them in the development process of the things, and integrate them organically to promote a harmonious social development state. For this point, Marx's thoughts and traditional culture have their own respective ideas and concepts on harmonious development, traditional culture pays more attention to harmony and moderation, however, Marxist philosophy pays more attention to seeking development in the contradictions, but these two ideas are still similar in nature, so this is one point of coincidence of them

\section{Exploration and Analysis on Contemporary Values of All-round Development Theory and Human Thoughts}

Human development is not only the topic that individuals focus on but also the topic that the whole society pays attention to. Under the idea of the talent development, the development and progress of society are closely related to the individuals' development. Marxist philosophy is closely related to our policies, which occupies a large space in the course of our historical and social development, and in seeking for the thoughts of individual development, Marx's theory of all-round development can give the individuals' corresponding guidance and direction, which has certain guiding significance, and the fusion and collision between Marxism and China's traditional culture indicates the academic value of Marxism as a new research perspective. The human thoughts of traditional culture is the result of the continuous development of our history and the condensation and expression of the wisdom of countless ancestors, and as the result of our history development, it is also has a certain guiding role in the individuals development in the exploration of the development thoughts of human beings. Based on the actual situation, both Marxism philosophy and our traditional culture are naturally endowed the certain practical values due to their long-term historical development, and give enough guidance in the human development thoughts.

Human development is a topic that the contemporary society is to explore. Although the all-round theory in Marxist philosophy and the human thoughts in traditional culture have a long term of existence, the ideas of "harmonious development" and "construction of spiritual world" in these two ideas have constructive effects on the human thoughts of human beings. In the process of choosing the development path and development goals, individuals can make more appropriate, scientific and reasonable decisions on the basis of their actual situations, under the guidance of the above two ideas. To sum up, Marx and traditional culture have great contemporary value on the development thoughts of human beings, on the one hand, the contemporary value embodies that it is in close contact with these two ideas and also plays a constructive and guiding role in the direction of personal development, on the other hand, these two ideas are also an important part of the development thoughts of human beings and has certain reference value for the academic circle. 


\section{Summary}

In summary, Marxism and traditional culture have several similarities in the human development thoughts, and their application in the modern society has certain practical significance and contemporary value, and it also possesses great significance to carry out corresponding research activities.

\section{References}

[1] Han Junlan, On the Realistic Basis of Sinicization of Marxism - And on the Contemporary Value of Chinese Traditional Culture [J], College counselor, 2011(05): 3-6[1].

[2] Luo Lijuan, Coincidence of Development Thoughts of Human Beings between Marx and Traditional Culture and Its Contemporary Values[D]. Shanxi University, 2016.

[3] Yang Dexiang, Marx's Religious Thought and the Research on Its Contemporary Values [D]. University of Electronic Science and Technology of China, 2015.

[4] Huang Youbin, A Study on the Contemporary Value of Chinese Traditional Culture from the Perspective of Marxism [D]. Yanbian University, 2013. 